\title{
Pharmacist and Physician Collaborative Practice Model Improves Vancomycin Dosing in an Intensive Care Unit
}

\author{
Dimitriy Levin ${ }^{1,2}$, Jeffrey J. Glasheen ${ }^{1,3}$, Tyree H. Kiser ${ }^{*}$ \\ ${ }^{1}$ Department of Medicine, University of Colorado, Aurora, Colorado, USA \\ ${ }^{2}$ University of Colorado Hospital Medicine Group, Aurora, Colorado, USA \\ ${ }^{3}$ University of Colorado Hospital Authority, Aurora, Colorado, USA \\ ${ }^{4}$ Department of Clinical Pharmacy, University of Colorado Skaggs School of Pharmacy and Pharmaceutical Sciences, Aurora, \\ Colorado, USA \\ Email: *ty.kiser@ucdenver.edu
}

How to cite this paper: Levin, D., Glasheen, J.J. and Kiser, T.H. (2016) Pharmacist and Physician Collaborative Practice Model Improves Vancomycin Dosing in an Intensive Care Unit. International Journal of Clinical Medicine, 7, 675-684. http://dx.doi.org/10.4236/ijcm.2016.710073

Received: August 29, 2016

Accepted: October 22, 2016

Published: October 25, 2016

Copyright $\odot 2016$ by authors and Scientific Research Publishing Inc. This work is licensed under the Creative Commons Attribution International License (CC BY 4.0).

http://creativecommons.org/licenses/by/4.0/ (c) $\underset{\mathrm{EY}}{\text { (i) Open Access }}$

\section{Abstract}

Objective: A pharmacist and physician collaborative practice intervention to improve the initial dosing of vancomycin was implemented with the goal of decreasing the number of subtherapeutic first troughs and increasing the number of therapeutic troughs. Methods: Using the best available evidence, a nomogram was created to determine the initial vancomycin dose. The nomogram utilized actual bodyweight and glomerular filtration rate (eGFR) estimated with the MDRD4 equation. The dose was based on the 2009 ASHP/IDSA/SIDP guidelines, which recommended 15 - 20 $\mathrm{mg} / \mathrm{kg}$ every 8 - 12 hours. Providers ordered "vancomycin IV dosed per pharmacy". Results: The pre- $(n=75)$ and post-intervention $(n=108)$ cohorts had similar age, gender distribution, weight, and eGFR. The median total daily vancomycin dose was similar in pre- and post-intervention groups $(2000 \mathrm{mg})$, although the median first trough was higher following the intervention ( 13.0 vs. $14.8 \mathrm{mcg} / \mathrm{ml}, \mathrm{p}=0.03)$. Following the intervention, the proportion of first troughs under $10 \mathrm{mcg} / \mathrm{ml} \mathrm{decreased}$ ( $32 \%$ to $13 \%, p=0.003$ ), while the proportion of troughs in the $10-20 \mathrm{mcg} / \mathrm{ml}$ therapeutic range increased $(50.7 \%$ vs. $69.4 \%, p=0.01)$. There was no difference in the proportion of troughs over $20 \mathrm{mcg} / \mathrm{ml}(17.3 \%$ vs. $17.6 \%, p=0.96)$. Conclusions: A multi-disciplinary intervention utilizing a nomogram-based pharmacy collaborative practice model significantly improves the proportion of therapeutic initial vancomycin troughs and decreases the number of subtherapeutic troughs by half.

\section{Keywords}

Vancomycin, Nomogram, Protocol, Collaborative Practice, 
Therapeutic Drug Monitoring

\section{Introduction}

Vancomycin is a glycopeptide antibiotic with activity against a variety of Gram-positive organisms, including methicillin-resistant Staphylococcus aureus (MRSA). It is commonly used as part of an empiric broad-spectrum antimicrobial regimen in critically ill patients. Vancomycin must be given intravenously when used for systemic infections, with dose adjustment for body weight and renal function [1].

Although there is a dearth of high-quality data on optimal dosing strategies for vancomycin, in 2009 the American Society of Health-System Pharmacists (ASHP), the Infectious Diseases Society of America (IDSA), and the Society of Infectious Diseases Pharmacists (SIDP) released joint consensus recommendations based on the best available evidence [1]. The expert panel recommended monitoring of steady-state vancomycin troughs with a goal level above $10 \mathrm{mcg} / \mathrm{ml}$ to avoid development of resistance. No preference was given to intermittent versus continuous dosing.

Vancomycin typically takes $36-48$ hours to reach a steady state. If the initial dose is incorrect, a patient may be severely under- or overdosed for a considerable period of time with risk of treatment failure, development of antimicrobial resistance, or vancomycin toxicity. To mitigate this, several nomograms have been published, targeting troughs greater than $5 \mathrm{mcg} / \mathrm{ml}[2]$ and $7.5 \mathrm{mcg} / \mathrm{ml}$ [3]. However, these nomograms were published before the emergence of heteroresistant and vancomycin-intermediate Staphylococcus aureus (VISA) strains and the publication of joint consensus recommendations to keep troughs over $10 \mathrm{mcg} / \mathrm{ml}$. The upper trough limit recommended in literature is 20 $\mathrm{mcg} / \mathrm{ml}$ based on the American Thoracic Society (ATS) and IDSA guidelines on hospital-acquired pneumonia [4] and IDSA guidelines on bacterial meningitis [5].

Given the interpatient variability and complexity of vancomycin dosing in intensive care unit patients, utilizing a multidisciplinary approach to therapy could improve time to therapeutic target attainment and patient safety. Pharmacists have specialty training in pharmacokinetics and pharmacodynamics and have demonstrated improvements in drug utilization and patient outcomes in outpatient collaborative practice models [6] [7]. However, most inpatient studies evaluate the impact of pharmacists rounding with a multidisciplinary team [8], with few published studies evaluating inpatient pharmacy collaborative practice endeavors that fully delegate drug therapy management to the pharmacist.

We undertook a quality improvement initiative at our institution to optimize initial vancomycin dosing using a nomogram and a pharmacy collaborative practice approach. The primary objective was to decrease the number of subtherapeutic troughs due to antibiotic under dosing.

\section{Methods}

The study was performed at the University of Colorado Hospital, a tertiary academic 
hospital. The study protocol was approved by the Colorado Multiple Institutional Review Board. Patient consent was not required and a Health Insurance Portability and Accountability Act waiver was obtained.

\subsection{Vancomycin Nomogram Design}

The nomogram was designed using current recommendations to dose vancomycin at $15-20 \mathrm{mg} / \mathrm{kg}$ every $8-12$ hours in patients with normal renal function (Table 1) [1]. The decision to use intermittent rather than continuous dosing was based on the lack of definitive benefit with the latter, balanced by increased complexity and logistics such as the need for dedicated intravenous access in patients already receiving continuous infusions of vasopressors, sedatives, and analgesics. Actual body weight was used for dosing, including in obese patients, based on the best current evidence [9]. Although doses up to $6000 \mathrm{mg}$ /day have been reported in literature [10], we capped the maximum initial dose at $4500 \mathrm{mg} /$ day (1500 mg every 8 hours) for safety. Since vancomycin clearance is strongly tied to renal function [3], dosing every 8 hours was prescribed for patients with very high estimated glomerular filtration rate (eGFR). The eGFR was calculated using the 4-variable Modification of Diet in Renal Disease (MDRD4) [11] equation using gender, age, creatinine, and race $\left[\mathrm{eGFR}=186 \times[\text { Serum Creatinine }(\mathrm{mg} / \mathrm{dL})]^{-1.154}\right.$ $\times \mathrm{Age}^{-0.203} \times(0.742$ if Female $) \times(1.210$ if African American $\left.)\right]$. Vancomycin doses were rounded to $250 \mathrm{mg}$ increments for dosing convenience. Therapeutic trough range was defined as $10-20 \mathrm{mcg} / \mathrm{ml}$. This trough range was designed to yield an Area Under the Curve to Minimum Inhibitory Concentration (AUC:MIC) ratio of $>400$ in the majority of patients, because the Staphylococcus aureus MIC at the University of Colorado Hospital is typically $\leq 1 \mathrm{mcg} / \mathrm{ml}$.

Table 1. Vancomycin nomogram.

\begin{tabular}{ccccc}
\hline \multirow{2}{*}{$\operatorname{eGFR}\left(\mathrm{ml} / \mathrm{min} / 1.73 \mathrm{~m}^{2}\right)$} & \multicolumn{4}{c}{ Actual bodyweight $(\mathrm{kg})$} \\
\cline { 2 - 5 } & $<60$ & $60-80$ & $81-100$ & $>100$ \\
\hline$>90$ & $750 \mathrm{mg} \mathrm{q} 8$ & $1000 \mathrm{mg} \mathrm{q} 8$ & $1250 \mathrm{mg} \mathrm{q} 8$ & $1500 \mathrm{mg} \mathrm{q} 8$ \\
$50-90$ & $750 \mathrm{mg} \mathrm{q} 12$ & $1000 \mathrm{mg} \mathrm{q} 12$ & $1250 \mathrm{mg} \mathrm{q} 12$ & $1500 \mathrm{mg} \mathrm{q} 12$ \\
$15-49$ & $750 \mathrm{mg} \mathrm{q} 24$ & $1000 \mathrm{mg} \mathrm{q} 24$ & $1250 \mathrm{mg} \mathrm{q} 24$ & $1500 \mathrm{mg} \mathrm{q} 24$ \\
$<15$ or RRT & $750 \mathrm{mg} \times 1$ & $1000 \mathrm{mg} \times 1$ & $1250 \mathrm{mg} \times 1$ & $1500 \mathrm{mg} \times 1$ \\
\hline
\end{tabular}

Therapeutic drug monitoring

1. For patients dosed every $8-12$ hours, check trough 30 minutes prior to 4 th dose

2. For patients dosed every 24 hours, check trough 30 minutes prior to 3 rd dose

Patients with eGFR $<15$, continuous RRT, or unstable renal function

1. Give a one-time dose per nomogram

2. Check a random vancomycin level 24 hours after the dose

3. If random level is $<20 \mathrm{mcg} / \mathrm{mL}$, repeat dose

4. If random level is $>20 \mathrm{mcg} / \mathrm{mL}$, do not redose, repeat random level in 12 hours

Patients on intermittent hemodialysis

1. Give a one-time dose per nomogram

2. Check a random vancomycin level 2 hours after hemodialysis

3. If random level is $<20 \mathrm{mcg} / \mathrm{mL}$, repeat dose

4. If random level is $>20 \mathrm{mcg} / \mathrm{mL}$, do not redose, repeat level after next dialysis

Dosing frequency is in hours (q8 = every 8 hours; q12 = every 12 hours; q24 = every 24 hours). eGFR = estimated glomerular filtration rate; RRT $=$ renal replacement therapy. 


\subsection{Collaborative Practice Implementation}

The vancomycin nomogram and the collaborative practice protocol were reviewed and approved by the University of Colorado Hospital Pharmacy and Therapeutics committee and were implemented per the Colorado State Boards of Medicine and Pharmacy collaborative practice model agreement. All clinical pharmacists involved in care of ICU patients were trained in nomogram use with a mandatory online educational module. Prescribing providers in ICUs were given a copy of the protocol and instructed to order "vancomycin IV dosed per pharmacy" rather than indicate dose and frequency, although providers were also allowed to override the protocol and order a different dose at their discretion. A clinical pharmacist then gathered the required demographic and laboratory information, calculated eGFR, and ordered the vancomycin dose from the nomogram. Additionally, the pharmacist ordered a vancomycin trough at an appropriate time prescribed per the protocol. Vancomycin pharmacokinetic tracking forms were reviewed on a weekly basis during the study period.

\subsection{Patient Population}

Adult patients started on vancomycin in the intensive care unit (ICU) were included regardless of body weight and renal function, including renal replacement therapy. Patient demographics, actual bodyweight, vancomycin dose, and vancomycin trough data was obtained from pharmacokinetic tracking forms filled out prospectively by ICU clinical pharmacists. Only patients without a measured vancomycin trough concentration were excluded from the study. Patients were divided into historical control and intervention groups. Historical data was obtained from records of patients treated during the 3 months prior to protocol initiation. Patients in the intervention group were treated under the collaborative practice protocol for the 6-month period post protocol initiation.

\subsection{Outcomes Evaluated}

The primary outcome of this study was the incidence of subtherapeutic initial vancomycin trough concentrations, defined as a first drawn steady-state trough value $<10$ $\mathrm{mcg} / \mathrm{ml}$ [1]. Secondary outcomes evaluated were the percentage of initial trough concentrations in goal range $(10-20 \mathrm{mcg} / \mathrm{ml})$, percentage of supratherapeutic trough concentrations $(>20 \mathrm{mcg} / \mathrm{ml})$, and the median daily vancomycin dose. Outcomes were compared between historical controls and the intervention group.

\subsection{Statistical Analysis}

Assuming subtherapeutic values in $34 \%$ of vancomycin trough concentrations $(<10$ $\mathrm{mcg} / \mathrm{ml}$ ) in the historical control group, a total of 70 patients were needed in each group to have an $80 \%$ power to detect a $20 \%$ absolute decrease in subtherapeutic vancomycin trough concentrations.

Statistical analysis of the results was performed with Microsoft Excel (Microsoft, Redmond, WA) and Statext 1.4.1 (Statext.com). Continuous variables were compared using the Mann-Whitney $U$ test and the Kruskal-Wallis one-way analysis of variance. 
Categorical variables were compared using the Fisher's exact test and the chi-square test for independence. All tests were 2-tailed. A p value less than 0.05 was considered statistically significant.

\section{Results}

\subsection{Patient Characteristics}

A total of 183 patients were enrolled in this study: 108 in the collaborative practice group and 75 in the historical control group. The suggested nomogram dosing regimen was used in 108/178 (60.1\%) of eligible patients during the intervention period. Demographics of the 75 historical controls and the 108 patients dosed under the collaborative practice agreement are shown in Table 2.

\subsection{Evaluation of Vancomycin Trough Concentrations}

Although there was no statistically significant difference in the median total daily dose of vancomycin, the intervention group had a significantly higher median initial trough ( $14.8 \mathrm{mcg} / \mathrm{ml}$, IQR 11.6 - 18.2, vs. $13.0 \mathrm{mcg} / \mathrm{ml}$, IQR $9.1-16.8, p=0.03$ ). The intervention group experienced a significant reduction in the proportion of subtherapeutic

Table 2. Patient characteristics at vancomycin initiation.

\begin{tabular}{|c|c|c|c|c|}
\hline \multirow{2}{*}{ Variable } & Controls & Non-users & Intervention & \multirow{2}{*}{$p$-value } \\
\hline & $(\mathrm{n}=75)$ & $(\mathrm{n}=70)$ & $(\mathrm{n}=108)$ & \\
\hline Age (years) & $56(47-64)$ & $52(39-62)$ & $53(42-64)$ & $p=0.4$ \\
\hline Male sex (\%) & 56 & 59 & 56 & $p=0.9$ \\
\hline Actual bodyweight (kg) & $85(66-97)$ & $88(64-107)$ & $78(67-96)$ & $p=0.7$ \\
\hline$<60 \mathrm{~kg}$ & $13 \%$ & $20 \%$ & $10 \%$ & $p=0.2$ \\
\hline $60-80 \mathrm{~kg}$ & $25 \%$ & $20 \%$ & $46 \%$ & $p<0.005$ \\
\hline $81-100 \mathrm{~kg}$ & $40 \%$ & $29 \%$ & $21 \%$ & $p=0.02$ \\
\hline$>100 \mathrm{~kg}$ & $21 \%$ & $31 \%$ & $22 \%$ & $p=0.3$ \\
\hline eGFR $\left(\mathrm{ml} / \mathrm{min} / 1.73 \mathrm{~m}^{2}\right)$ & $89(56-109)$ & $81(54-114)$ & $70(47-102)$ & $p=0.2$ \\
\hline$<15$ or RRT & $12 \%$ & $24 \%$ & $15 \%$ & $p=0.1$ \\
\hline $15-49$ & $19 \%$ & $11 \%$ & $19 \%$ & $p=0.4$ \\
\hline $50-90$ & $32 \%$ & $24 \%$ & $39 \%$ & $p=0.1$ \\
\hline$>90$ & $37 \%$ & $40 \%$ & $28 \%$ & $p=0.2$ \\
\hline Vancomycin TDD (mg) & $2000(2000-2250)$ & $2000(1250-3000)$ & $2000(1250-2500)$ & $p=0.5$ \\
\hline
\end{tabular}

Data presented as proportions or median (interquartile range). eGFR = estimated glomerular filtration rate; RRT = renal replacement therapy; TDD = total daily dose. 
troughs $<10 \mathrm{mcg} / \mathrm{ml}$ (32.0\% to $13.0 \%, p=0.003)$, a significant increase in the number of in-range troughs $10-20 \mathrm{mcg} / \mathrm{ml}(50.7 \%$ to $69.4 \%, p=0.01)$, and no significant change in supratherapeutic troughs $>20 \mathrm{mcg} / \mathrm{ml}(17.3 \%$ to $17.6 \%, p=0.96)$ compared to historical control patients (Figure 1). The 70 patients who were not dosed using the collaborative practice option during the intervention period had a trough distribution similar to historical controls (27.1\% low, $51.4 \%$ in-range, and $21.4 \%$ high; $p=0.02$ for proportion of low and in-range groups compared to the collaborative practice nomogram cohort, $p=0.5$ for comparison of supratherapeutic groups).

\subsection{Evaluation of Vancomycin Troughs in Weight and eGFR Subgroups}

The nomogram also performed well in subsets of patients at the extremes of weight and renal function (Table 3). Compared to historical controls and collaborative practice non-users, the intervention group had more patients with therapeutic troughs among those weighing $60-80 \mathrm{~kg}(p=0.01)$. There was a trend towards significant improvement in therapeutic troughs in subgroups with body weight under $60 \mathrm{~kg}(p=0.05)$ and eGFR $>90 \mathrm{ml} / \mathrm{min} / 1.73 \mathrm{~m}^{2}(p=0.08)$.

100

- Historical Controls $\square$ Post-intervention non-users $\square$ Intervention group 90

80

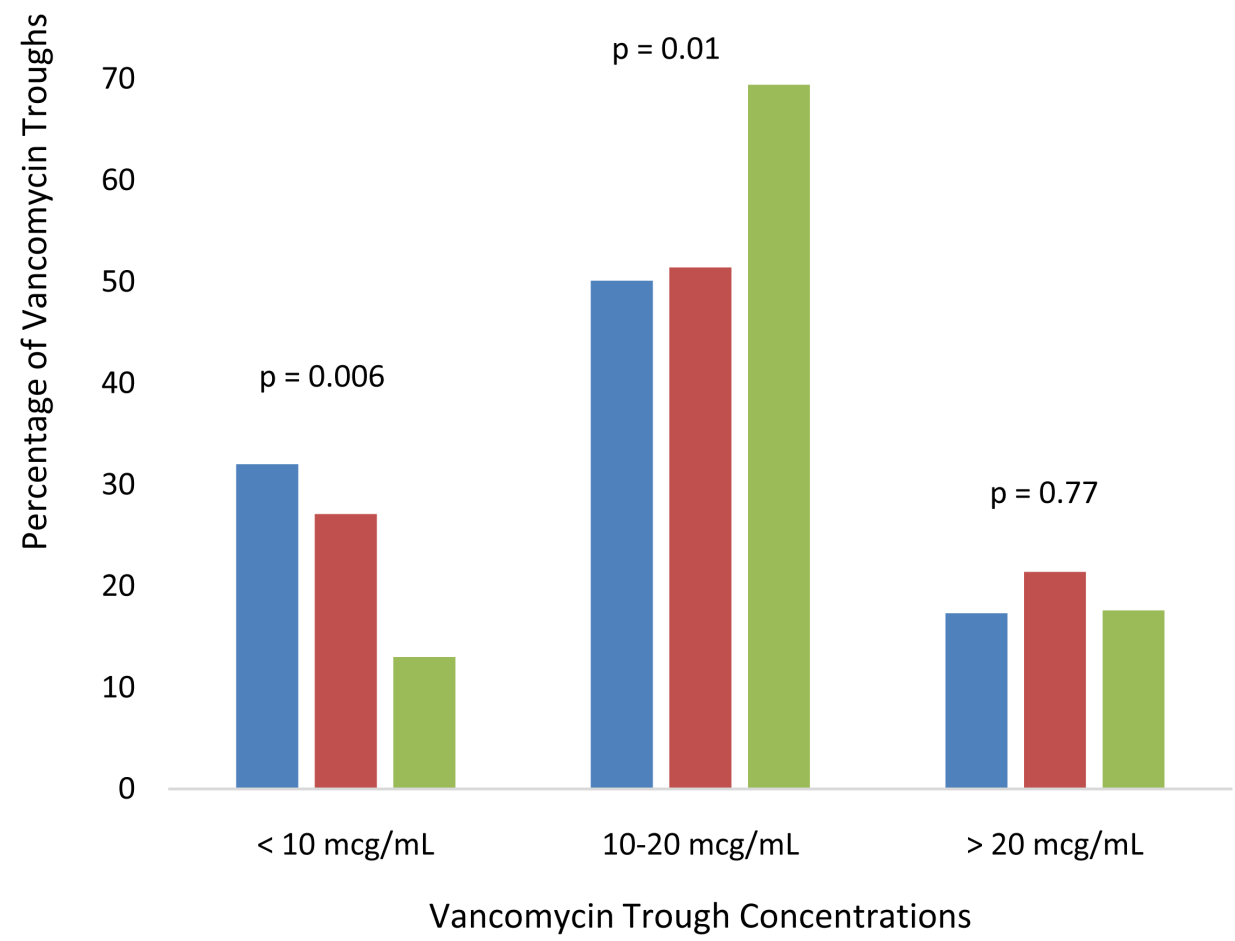

Figure 1. Distribution of initial vancomycin troughs among historical controls, patients not dosed per nomogram during the intervention period (non-users), and patients dosed using the collaborative intervention nomogram. 
Table 3. Proportion of vancomycin troughs in therapeutic $(10-20 \mathrm{mcg} / \mathrm{ml})$ range in historical controls, nomogram non-users, and nomogram-dosed patients at the extremes of weight and renal function.

\begin{tabular}{ccccc}
\hline & Controls & Non-users & Intervention & \multirow{2}{*}{$p$-value } \\
\cline { 2 - 4 } & $(\mathrm{n}=75)$ & $(\mathrm{n}=70)$ & $(\mathrm{n}=108)$ & \\
\hline Actual bodyweight $(\mathrm{kg})$ & & & & \\
$<60$ & $4 / 10(40 \%)$ & $5 / 14(36 \%)$ & $9 / 11(82 \%)$ & $p=0.05$ \\
$60-80$ & $6 / 19(32 \%)$ & $7 / 14(50 \%)$ & $36 / 50(72 \%)$ & $p=0.01$ \\
$81-100$ & $18 / 30(60 \%)$ & $10 / 20(50 \%)$ & $14 / 23(61 \%)$ & $p=0.7$ \\
$>100$ & $10 / 16(63 \%)$ & $14 / 22(64 \%)$ & $16 / 24(67 \%)$ & $p=0.9$ \\
eGFR $\left(\mathrm{ml} / \mathrm{min} / 1.73 \mathrm{~m}^{2}\right)$ & & & & \\
$<15$ or RRT & $5 / 9(56 \%)$ & $9 / 17(53 \%)$ & $12 / 16(75 \%)$ & $p=0.4$ \\
$15-49$ & $8 / 14(57 \%)$ & $6 / 8(75 \%)$ & $14 / 20(70 \%)$ & $p=0.6$ \\
$50-90$ & $12 / 24(50 \%)$ & $9 / 17(53 \%)$ & $28 / 42(67 \%)$ & $p=0.4$ \\
$>90$ & $13 / 28(46 \%)$ & $12 / 28(43 \%)$ & $21 / 30(70 \%)$ & $p=0.08$ \\
\hline
\end{tabular}

eGFR = estimated glomerular filtration rate; $\mathrm{RRT}=$ renal replacement therapy.

\section{Discussion}

We have demonstrated that a physician and pharmacist collaborative practice-based quality improvement initiative utilizing an evidence-based nomogram can successfully improve initial vancomycin dosing in critically ill patients. Our primary objective was to minimize the risk of underdosing and subsequent promotion of antimicrobial resistance, and in that respect $87 \%$ of patients dosed with the nomogram had an initial trough $\geq 10 \mathrm{mcg} / \mathrm{ml}$. Although our nomogram was only $69 \%$ successful in reaching the therapeutic range of $10-20 \mathrm{mcg} / \mathrm{ml}$, this is significantly better than provider-initiated dosing at our institution ( $44 \%-51 \%)$ and in published studies of non-nomogram dosing (34\%) [12]. While another previously published nomogram was $94 \%$ accurate [2], it targeted a much broader trough range of $5-20 \mathrm{mcg} / \mathrm{ml}$. Accuracy of our protocol might have been adversely affected by the dynamic nature of ICU patients. Vancomycin clearance is strongly tied to renal function and since critically ill patients often have dynamic renal function, pinpointing an accurate eGFR can be challenging.

We observed a significant increase in the median vancomycin troughs without a corresponding change in the median total daily dose, as well as a decrease in subtherapeutic troughs without a concurrent increase in supratherapeutic troughs. This supports that patients were dosed more correctly for their bodyweight and renal function rather than simply receiving a higher dose across the board. The fact that provider-initiated dosing during the intervention period did not significantly differ from the historical controls favors the improvement being due to implementation of the nomogram.

It is important to note that our historical and non-user groups significantly differed from the nomogram cohort in certain weight subgroups. It is unclear whether this reflects our small sample size, a seasonal variation in ICU patients, or both. Unfortunate- 
ly, analysis of all subgroups was limited by small sample size and a Type II error cannot be ruled out. Nevertheless, our data suggest improvement due to use of the nomogram in patients weighing less than $80 \mathrm{~kg}$, and a trend toward significance with eGFR $>90$ $\mathrm{ml} / \mathrm{min} / \mathrm{m}^{2}$.

Additional limitations of this study include a small sample size, application at a single hospital, and lack of clinical and microbiologic outcome data. Staphylococcus aureus MICs at our institution are typically $\leq 1 \mathrm{mcg} / \mathrm{ml}$, so our nomogram was not directly designed to achieve the narrower trough serum concentration of $15-20 \mathrm{mcg} / \mathrm{ml}$ in all patients. Patients were only enrolled from the medical intensive care unit, so the applicability of our nomogram to other patient populations is unknown.

A large number of patients during the intervention period were dosed without the nomogram. This reflects the inherent challenge of implementing quality improvement initiatives that rely on changing behavior. Prior to the collaborative practice model, we attempted to educate providers to directly use the nomogram with a nearly zero-use rate despite frequent personal communication with physicians. Following roll-out of the collaborative practice, providers chose to bypass this process even though ordering "vancomycin per pharmacy" was easier than ordering a specific dose. We do not know if this was done for reasons of clinical judgment or because they did not know that this option was available. If clinical judgment was the reason for non-adherence, our findings of the non-nomogram group performing comparably to controls identify a potential knowledge and skill gap. Although clinical pharmacists were encouraged to call providers to encourage them to use the nomogram, this did not reliably happen because of workload issues and logistics.

In the course of this project, we were reminded of the scarcity of high-quality data on vancomycin dosing. With the advent of vancomycin-intermediate heteroresistant pathogens, a minimum trough of $15 \mathrm{mcg} / \mathrm{ml}$ may be required to avoid treatment failures. The narrow therapeutic range of $15-20 \mathrm{mcg} / \mathrm{ml}$ would be exceedingly difficult to attain even with the best dosing practices and high-quality research is urgently needed to establish the safe upper limit for vancomycin doses using the modern formulation of the antibiotic.

Finally, this study demonstrates that a physician and pharmacist collaborative practice model lends itself well to medications with complex dosing and monitoring requirements and should be explored as an effective quality improvement solution.

\section{Conclusion}

Utilization of an inpatient pharmacy collaborative practice model to manage vancomycin therapy resulted in a significant reduction in subtherapeutic trough concentrations and increased the percentage of therapeutic trough concentrations. This was accomplished without increasing the percentage of supratherapeutic trough concentrations. This inpatient multidisciplinary collaborative practice model should be evaluated in broader drug categories and patient populations to ensure reproducibility of these findings. 


\section{Acknowledgements}

The authors would like to acknowledge Gerry Barber, RPh MPH, Michelle Barron, MD, Larry Golightly, PharmD, and Jonathan Pell, MD, for their assistance in design and implementation of this project. The authors acknowledge the following University of Colorado Hospital physicians and pharmacists for participating and contributing to the success of the collaborative practice model: Craig Anthony, PharmD, Bonnie Boller, PharmD, Ellen Burnham, MD, Sarah Carson, PharmD, Lisa Dufficy, PharmD, Douglas Fish, PharmD, Dennise Luby, PharmD, Robert MacLaren, PharmD, Scott Mueller, PharmD, Deborah Sherman, PharmD, Cathryn Todd, PharmD, Jessica Wittmer, PharmD, and the University of Colorado physicians and housestaff

Preliminary data presented in poster format at: The Society of Hospital Medicine Annual Meeting 2010, Abstract \#87. Levin D., Kiser T. A Multidisciplinary Intervention Improves Vancomycin Dosing in the Intensive Care Unit [abstract]. Journal of Hospital Medicine, 2010, 5 (suppl 1),

http://www.shmabstracts.com/abstract/a-multidisciplinary-intervention-improves-vanc omycin-dosing-in-the-intensive-care-unit/.

\section{Conflict of Interest}

The authors declare that they have no conflict of interest.

\section{References}

[1] Rybak, M., Lomaestro, B., Rotschafer, J.C., et al. (2009) Therapeutic Monitoring of Vancomycin in Adult Patients: A Consensus Review of the American Society of Health-System Pharmacists, the Infectious Diseases Society of America, and the Society of Infectious Diseases Pharmacists. American Society of Health System Pharmacists, 66, 82-98. http://dx.doi.org/10.2146/ajhp080434

[2] Karam, C.M., McKinnon, P.S., Neuhauser, M.M. and Rybak, M.J. (1999) Outcome Assessment of Minimizing Vancomycin Monitoring and Dosing Adjustments. Pharmacotherapy, 19, 257-266. http://dx.doi.org/10.1592/phco.19.4.257.30933

[3] Matzke, G.R., McGory, R.W., Halstenson, C.E. and Keane, W.F. (1984) Pharmacokinetics of Vancomycin in Patients with Various Degrees of Renal Function. Antimicrobial Agents and Chemotherapy, 25, 433-437. http://dx.doi.org/10.1128/AAC.25.4.433

[4] Niederman, M.S., Craven, D.E., Bonten, M.J., et al. (2005) Guidelines for the Management of Adults with Hospital-Acquired, Ventilator-Associated, and Healthcare-Associated Pneumonia. American Journal of Respiratory and Critical Care Medicine, 171, 388-416. http://dx.doi.org/10.1164/rccm.200405-644ST

[5] Tunkel, A.R., Hartman, B.J., Kaplan, S.L., et al. (2004) Practice Guidelines for the Management of Bacterial Meningitis. Clinical Infectious Diseases, 39, 1267-1284. http://dx.doi.org/10.1086/425368

[6] Koshman, S.L., Charrois, T.L., Simpson, S.H., McAlister, F.A. and Tsuyuki, R.T. (2008) Pharmacist Care of Patients with Heart Failure. Archives of Internal Medicine, 168, 687694. http://dx.doi.org/10.1001/archinte.168.7.687

[7] Nkansah, N., Mostovetsky, O., Yu, C., et al. (2010) Effect of Outpatient Pharmacists' NonDispensing Roles on Patient Outcomes and Prescribing Patterns. Cochrane Database of 
Systematic Reviews, 7, CD000336. http://dx.doi.org/10.1002/14651858.cd000336.pub2

[8] Makowsky, M.J., Koshman, S.L., Midodzi, W.K. and Tsuyuki, R.T. (2009) Capturing Outcomes of Clinical Activities Performed by a Rounding Pharmacist Practicing in a Team Environment: The Collaborate Study. Medical Care, 47, 642-650.

http://dx.doi.org/10.1097/MLR.0b013e3181926032

[9] Bearden, D.T. and Rodvold, K.A. (2000) Dosage Adjustments for Antibacterials in Obese Patients. Clinical Pharmacokinetics, 38, 415-426.

http://dx.doi.org/10.2165/00003088-200038050-00003

[10] Bauer, L.A., Black, D.J. and Lill, J.S. (1998) Vancomycin Dosing in Morbidly Obese Patients. European Journal of Clinical Pharmacology, 54, 621-625.

http://dx.doi.org/10.1007/s002280050524

[11] Levey, A.S., Coresh, J., Greene, T., et al. (2007) Expressing the Modification of Diet in Renal Disease Study Equation for Estimating Glomerular Filtration Rate with Standardized Serum Creatinine Values. Clinical Chemistry, 53, 766-772.

http://dx.doi.org/10.1373/clinchem.2006.077180

[12] Kitzis, M.D. and Goldstein, F.W. (2006) Monitoring of Vancomycin Serum Levels for the Treatment of Staphylococcal Infections. Clinical Microbiology and Infection, 12, 92-95. http://dx.doi.org/10.1111/j.1469-0691.2005.01306.x

Submit or recommend next manuscript to SCIRP and we will provide best service for you:

Accepting pre-submission inquiries through Email, Facebook, LinkedIn, Twitter, etc. A wide selection of journals (inclusive of 9 subjects, more than 200 journals)

Providing 24-hour high-quality service

User-friendly online submission system

Fair and swift peer-review system

Efficient typesetting and proofreading procedure

Display of the result of downloads and visits, as well as the number of cited articles

Maximum dissemination of your research work

Submit your manuscript at: http://papersubmission.scirp.org/

Or contact ijcm@scirp.org 